\title{
Living for the weekend: electronic documentation improves patient handover
}

\author{
Matthew Govier and Pippa Medcalf
}

\begin{abstract}
With increasing shift work the importance of effective handover is becoming more widely recognised, resulting in the production of guidelines on written handover documentation. A particular area of poor compliance was handover from the week to weekend teams for medical inpatients, as shown through an audit cycle. Full implementation of any guidelines can be time and financially costly. However, a simple, minimal cost, electronic-based list improved the quantitative measures of written handover, particularly in areas of patient location, resuscitation status and investigations. Qualitative data showed multiple benefits, but also problems with logistics in computer terminals, networks and access. Solutions to such problems are discussed, with the importance of carefully implemented longer term changes being emphasised.
\end{abstract}

KEY WORDS: documentation, handover, patient safety, weekend

\section{Introduction}

In 1996, it was reported that over $80 \%$ of written handover was described as 'less than adequate' by junior doctors. ${ }^{1}$ However, with increasing shift work, the importance of effective and safe handover became more widely recognised - exemplified by its incorporation into the General Medical Council's Good medical practice document $^{2}$ and the Foundation Programme competencies. ${ }^{3}$

To achieve a consistently high level in the practice of handover, the Royal College of Physicians (RCP), Royal College of Surgeons $(\mathrm{RCS})^{4-6}$ and the British Medical Association (BMA) ${ }^{7}$ developed recommendations and guidelines to be implemented locally.

These emphasised thinking about the 'who, what, where, when and how' of handover; in particular having available an electronic-based 'live-list' for all current inpatients, alongside the faceto-face verbal handover. Transfer of responsibility from the day team to the hospital-at-night team and the weekend on-call team is highlighted as a particularly important area, where effective handover is paramount. The use of electronic handover from the day to night team has previously been shown to be beneficial, ${ }^{8}$ but less information exists around the use of electronic handover from the week day to the weekend teams.

Matthew Govier, foundation year 2, Royal United Hospital, Royal United Hospital Bath NHS Trust; Pippa Medcalf, consultant physician, Gloucestershire Royal Hospital, Gloucestershire Hospitals NHS Foundation Trust
This article describes the process undertaken to implement a short-term improvement in electronic written handover for the weekend, in a 680-bedded district general hospital with 340 medical beds and an average emergency take of 40-60 patients per day, while longer term solutions were being investigated.

\section{Background}

The Gloucestershire Royal Hospital medical directorate holds a Friday lunchtime meeting, so patient details and plans may be verbally handed over to the weekend on-call team. The meeting is attended by at least one member of each medical specialties' day team, alongside the whole on-call team for the weekend ahead. Any patients requiring review and input over the weekend, or those with the potential to deteriorate, are verbally handed over. Details including history of admission, pending investigations, current plans and resuscitation status are discussed for each patient handed over.

Documentation of this handover was variable - the on-call team would often take handwritten notes of the details given verbally at the meeting; and the day teams might leave a printed or handwritten list on their ward with similar details. However, there was no expectation that either of these processes would occur. It was also not uncommon that one of the weekend team was not able to attend the meeting, either due to commitments on a Friday, or because the shift was to be covered by a locum doctor. The same applied to the day teams.

This variability led us to investigate whether such a system for written handover of general medical inpatients at a weekend complied with current handover guidelines. An audit cycle seemed an appropriate way to establish and improve such compliance, although some may prefer to describe this work as a service improvement project given that the plan was to introduce the new system before the original audit. Current guidelines were established from the RCP, ${ }^{4,5} \mathrm{RCS}^{6}$ and the BMA, ${ }^{7}$ as detailed in Box 1. The guidelines are designed to be applied to all current inpatients; however with the wish to implement a rapid and effective short-term change, they were initially applied to a smaller group who could potentially benefit the most from any intervention - those patients specifically handed over at the Friday meeting as requiring input, or those expected to deteriorate over the weekend.

\section{Audit method}

A list of patients verbally handed over for the weekend of 23 and 24 January 2010 was generated from the weekend 
Box 1. British Medical Association/Royal College of Physicians/Royal College of Surgeons guidelines on written handover.

$1100 \%$ of patients being handed-over to the on-call team should have a written handover, ideally as an electronic 'live-list'.

$2100 \%$ of the following details should be available for all patients being handed over:

- patient demographics:

name, age/date of birth, unique identifier

- current admission:

date of admission, location, responsible consultant

- medical details:

background, diagnosis, history of admission,

current problems, resuscitation status

- investigations/plan:

bloods, investigation results, pending investigations,

management plan, frequency of review.

handover meeting. All of these patients were included in the audit.

A trialled, standardised proforma was used to analyse which of the guideline-recommended patient details were contained in the written handover documentation of these patients. Written handover documentation included job lists left on the ward and any weekend summaries contained in the medical notes. The data were collated and analysed, with the results presented to the acute medicine directorate and the Friday verbal handover meeting.

This was followed by creation and implementation of a locally peer-reviewed, electronic spreadsheet system for written weekend handover. The spreadsheet was designed on Microsoft Office Excelø, and incorporated recommendations proposed by Cheah et al ${ }^{9}$ including the ability to:

- print a patient list for the wards being covered

- sort the list by ward, consultant or need for review

- allow handover information to be entered efficiently.

It was stored on the secure medicine hard-drive, which all doctors working in the medical directorate have access to from any internal terminal, via their password protected individual log-in. Each ward had an individual spreadsheet, which the day team would complete on a Friday, prior to the verbal handover meeting, with all patients they wished to hand over to the weekend team. The details contained on the spreadsheet were designed to comply with the current national handover guidelines (Fig 1). The weekend on-call team was encouraged to utilise these spreadsheets as their job lists, add to them if there were new jobs which became apparent, and tick off completed jobs.

Re-audit using the same methods for patient list generation and proforma was undertaken on 10-11 July 2010, a month after introduction of the spreadsheet system.

\section{Quantitative results}

Forty-three patients were identified and included in the initial audit cycle, and 73 patients for the re-audit. In the initial cycle, $86 \%$ of patients had some form of written handover available for analysis, of which $0 \%$ was as an electronic list. Post-intervention re-audit showed an increase to $100 \%$ having written handover, of which $86.3 \%$ was electronic list based.

The results of details contained in each of the summaries available are shown in Table 1.

\section{Qualitative results}

Informal discussion was undertaken at the Friday verbal handover meeting and with individual weekend on-call doctors, regarding their views on the new spreadsheets by one of the authors (MG). Positive points included having a persistent soft copy record of information handed over, instead of a single handwritten hard copy which could be accidentally lost, moved around the ward or destroyed, with no replacement. It was also commented that the use of electronic records should promote patient confidentiality, but most doctors admitted to printing off hard copies as the computer systems were too slow and inaccessible to allow efficient use during busy weekend shifts.

Formalisation of the written handover process was felt to be useful, the day teams had a standardised method including a reminder of all the required information, as well as a safe location to save information. The weekend on-call team also knew where the information would be located, rather than having to search the ward for handwritten lists. However, access to the

\begin{tabular}{|c|c|c|c|c|c|c|c|c|c|c|c|c|}
\hline \multirow{2}{*}{\multicolumn{2}{|c|}{$\begin{array}{c}\text { Job Day } \\
\text { Y or } \mathrm{N}\end{array}$}} & Bed & Name & MRN & DoB & Consultant & Background & Current Admission & For Resus & \multicolumn{2}{|c|}{ Job for weekend } & \multirow{3}{*}{$\begin{array}{l}\text { Job completed? } \\
\text { Bloods taken -T } \\
\text { Bloods checked -C } \\
\text { Review/other complete -Y }\end{array}$} \\
\hline & & & & & & \multirow{2}{*}{ Code } & \multirow{2}{*}{$\begin{array}{c}\text { Past Me dical } \\
\text { History }\end{array}$} & \multirow{2}{*}{$\mathrm{Hx}, \mathrm{Ix}$ and $\mathrm{o}$ igory Plan } & \multirow{2}{*}{ Yor N } & \multirow{2}{*}{ Job } & \multirow{2}{*}{$\begin{array}{l}\text { Recommended } \\
\text { action }\end{array}$} & \\
\hline Sat & Sun & & & & & & & & & & & \\
\hline $\mathrm{Y}$ & Y & 36 & $\mid \begin{array}{c}\text { John Smith } \\
\text { (Example) }\end{array}$ & 123456 & 1.01 .40 & AXA & $\begin{array}{c}\text { IHD, chronic } \\
\text { pain from OA, } \\
\text { taking } \\
\text { NSAIDs OTC. }\end{array}$ & $\begin{array}{l}\text { Melaena and lethargy. Hb } \\
6.8 \text { or admission. Trans- } \\
\text { fused } 4 \text { units RBCs. OGD- } \\
\text { GU with adherant clot IV } \\
\text { PPI, CV and HB stable } \\
\text { malaena ongoing. }\end{array}$ & Y & $\begin{array}{l}\text { Daliy } \\
\text { bloods } \\
\text { for HB }\end{array}$ & $\begin{array}{c}\text { If } \mathrm{Hb} \text { drops with } \\
\text { ongoing malaena } \\
\text { transfuse if }<8 \mathrm{~g} / \mathrm{dl} \\
\text { and discuss re-scope } \\
\text { with endoscopist } \\
\text { on-call }\end{array}$ & \\
\hline
\end{tabular}

Fig 1. Example spreadsheet for written weekend handover. 
hard-drive where the spreadsheets were stored proved problematic. Access was easily gained for those doctors employed by the trust, but locum doctors could not be granted such access and thus relied on other doctors to print off hard copies, which slowed down the process.

The idea of using the spreadsheets to include new jobs which occurred during the weekend was welcomed, as rarely did the same doctors cover the same areas for both Saturday and Sunday. However, it's usefulness as a 'live job list' during the day, for completing when bloods had been taken and checked, or reviews performed, was limited. Time constraints paired with a slow computer network prevented such realtime updates being undertaken, and thus the lists were updated with all new information at the same time, normally at the end of the day.

\section{Discussion}

Prior to introduction of the new spreadsheets, the written weekend handover of acutely unwell medical patients at Gloucestershire Royal Hospital was highly variable and poorly compliant with national standards. Local standardisation of this process to an electronic-based system has made substantial improvements, particularly in handover of patients' locations, current investigations, results, ongoing management plans and, perhaps most importantly in some ways, their resuscitation status. A large increase in the number of patients handed over, from 43 to 73 , also occurred. This is positive as more easily accessible knowledge about larger numbers of patients should increase patient care and safety; but in a negative light, did all of these patients actually require input over the weekend, or did the new system make handover so much simpler that non-urgent jobs were being handed over?

Because of problems with printing of the full handover list, the number of columns had to be decreased after initial trial of the spreadsheet. Thus the two details which could easily and quickly be obtained from other locations (ward boards, patient notes or the nursing staff) had their spreadsheet columns removed. Because of this the post-intervention, percentages for date of admission and responsible consultant are considerably lower than the other parameters. There are potential risks involved with printing off patient-identifiable data.

The importance of ensuring access and ease of use in electronic databases is also highlighted. Designing a database to certain specifications is relatively simple, but ensuring it is utilised is more complex. This begins with ensuring that all doctors using an electronic-based handover system have access to the required hard-drive area, formal training in how to access and update the lists, and who to contact should they have problems with the system. There are also a number of organisational areas which need addressing, including the number of computers and speed of the network. An interesting, although costly, initiative could be the use of electronic tablets/smart phones/personal digital assistants to overcome the burden of having to find and log onto a new computer every time a doctor changes wards.
Table 1. Specific details included in available written summaries.

\begin{tabular}{lll} 
Criterion & \multicolumn{2}{c}{ Percentage (\%) } \\
& Initial audit & Re-audit \\
Name & 100 & 100 \\
Age/date of birth & 56.8 & $\mathbf{9 3 . 2}$ \\
Unique identifier & 100 & $\mathbf{9 1 . 8}$ \\
Date of admission & 13.5 & 0 \\
Location & 40.5 & $\mathbf{9 8 . 6}$ \\
Responsible consultant & 2.7 & 0 \\
Background/previous medical history & 70.3 & $\mathbf{9 5 . 9}$ \\
Diagnosis & 86.5 & $\mathbf{9 8 . 6}$ \\
History of admission & 64.9 & $\mathbf{9 8 . 6}$ \\
Current problems & 86.5 & $\mathbf{9 8 . 6}$ \\
Resuscitation status & 13.5 & $\mathbf{8 7 . 7}$ \\
Bloods & 27.0 & $\mathbf{9 8 . 6}$ \\
Results of significant investigations & 51.4 & $\mathbf{9 8 . 6}$ \\
Pending investigations & 91.9 & $\mathbf{9 8 . 6}$ \\
Frequency of review & 89.2 & $\mathbf{1 0 0}$ \\
Management plan & 75.7 & $\mathbf{9 8 . 6}$ \\
& &
\end{tabular}

However, there are also significant issues with maintaining patient confidentiality if such devices are utilised. ${ }^{10}$

Although we have focused on those patients specifically handed over at a weekend, the national guidelines recommend that all patients have an electronic record of the details listed in Box 1. This is a long-term prospect and would require extensive planning, education and implementation. Any such change would likely benefit from the use of commercially produced software specific for the role of handover and patient records. Such software should also allow the prioritisation of patient review to be clearly highlighted, as previously recommended by Cheah et al. ${ }^{9}$ The importance of involvement of the full multidisciplinary team for data input, update and removal in any such electronic record would be vitally important. This intervention was intentionally a short-term measure to improve patient care and safety, while a longer-term plan is being discussed and implemented. Ideally we would have gained access for all members of the multidisciplinary team to our spreadsheets so handover information and jobs could be updated more easily. However, due to the workload and data protection this was not possible in a short timeframe.

\section{Conclusion}

A locally established, standardised and electronic written handover system can ensure effective transfer of responsibility for patients to the weekend on-call team. Such systems should adhere to nationally produced guidelines and electronic solutions can be achieved simply, with minimal expenditure for a short-term measure, while longer-term changes are carefully implemented. Achieving high standards in written handover should, in turn, improve patient safety, error avoidance and continuity of care. 
Since this work was carried out, the RCP has updated its guidelines for handover, ${ }^{11}$ which appear excellent and complement this proposed handover tool. The audit will be repeated in accordance with these new guidelines.

\section{References}

1 Roughton VJ, Severs MP. Junior doctor handover: current practices and future expectations. J R Coll Physicians Lon 1996;30;213-4.

2 General Medical Council. Good medical practice. London: GMC, 2006, updated March 2009.

3 Foundation Programme Curriculum, June 2007. www.foundationprogramme.nhs.uk/pages/home/key-documents

4 Metz D, Chard D, Rhodes J, Pounder P. Continuity of care for medical inpatients: standards of good practice. London: Royal College of Physicians, 2004

5 Royal College of Physicians. Guide for trainees and trainers: general professional training guide. London: RCP, 2005.

6 The Royal College of Surgeons of England. Safe handover: guidance from the Working Time Directive working party. London: RCS, 2007. www.rcseng.ac.uk/publications/docs/publication.2007-05$14.3777986999 /$.

7 British Medical Association. Safe handover: safe patients. Guidance on clinical handover for clinicians and managers. London: BMA, 2004.

8 Raptis DA, Fernandes C, Chua W. Electronic software significantly improves quality of handover in a London teaching hospital. Health Inform J 2009;15:191-8.

9 Cheah LP, Arnott DH, Pollard J. Electronic medical handover: towards safer medical care. Med J Aust 2005;183:369-72.

10 Wilcox RA, La Tella RR. The peronal digital assistant: a new medical instrument for the exchange of clinical information at the point of care. Med J Aust 2001;175:659-62.

11 www.rcplondon.ac.uk/resources/professionalism/acute-care-toolkit.

Address for correspondence: Dr M Govier,

Royal United Hospital, Royal United Hospital Bath NHS Trust, Combe Park, Bath BA1 3NG.

Email: matthew.govier@nhs.net

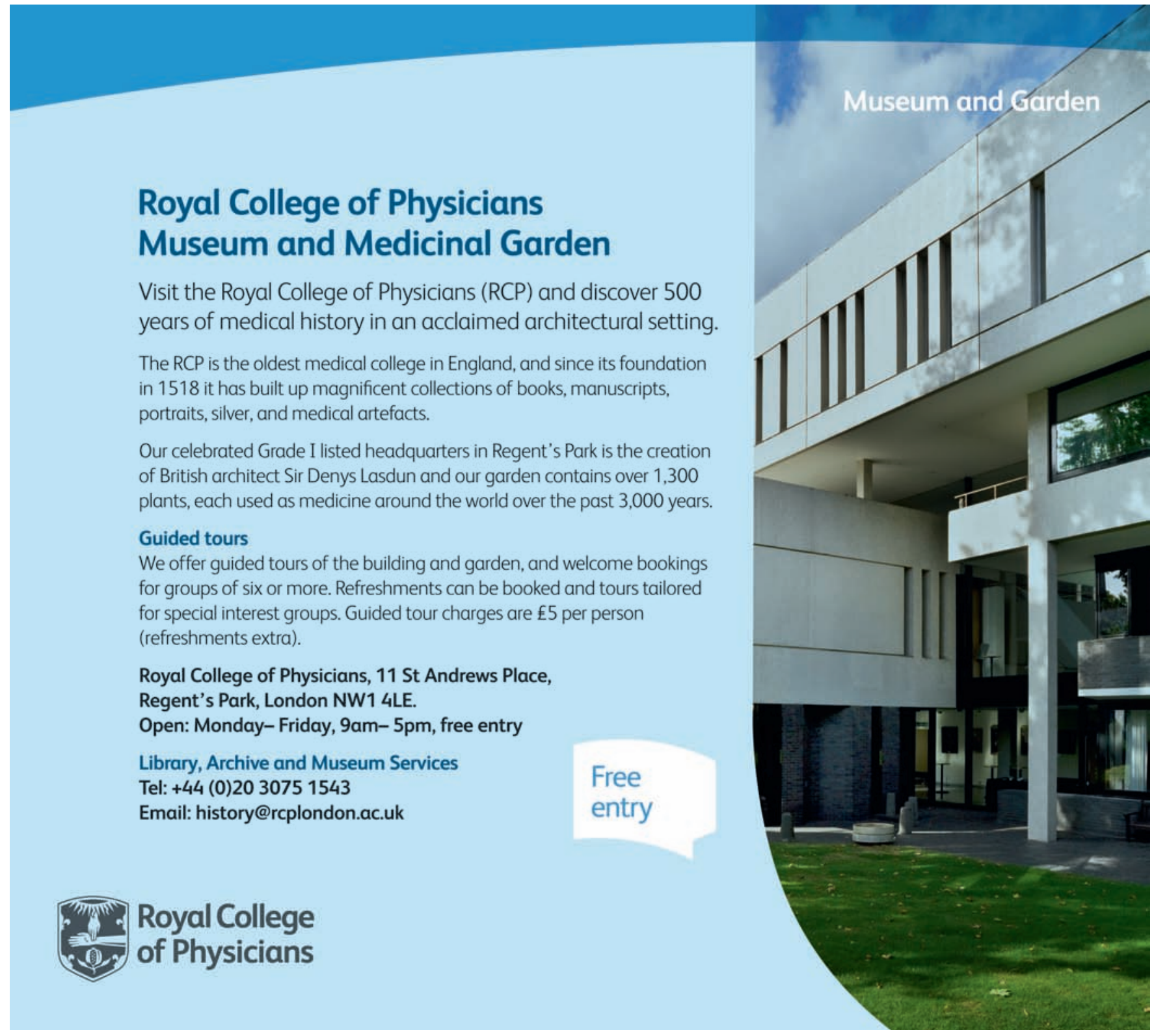

